\title{
La prioridad del Igualitarismo Democrático
}

\section{(The priority of Democratic Egalitarianism)}

\author{
Facundo GARCÍA VALVERDE
}

Recibido: 11 de junio de 2014

Aceptado: 5 de octubre de 2015

\section{Resumen}

Este artículo mostrará que las versiones estrictas del Igualitarismo Democrático y del Igualitarismo de la Suerte son implausibles ya que defienden una visión monista del objeto de la justicia igualitaria. Por el contrario, sus versiones moderadas son aceptables ya que admiten la composición plural del objeto de justicia igualitaria.

Esta comprensión plural exige, sin embargo, el establecimiento de prioridades normativas ya que las exigencias de cada valor entran típicamente en conflicto. Aquí, se ofrecerán tres argumentos para defender la prioridad del Igualitarismo Democrático sobre el Igualitarismo de la Suerte: uno instrumental, otro relacionado con el significado expresivo de las políticas públicas estatales y un último que justifica la división del trabajo moral igualitarista.

Palabras clave: Igualitarismo, respeto, status igual, equidad, responsabilidad.

\begin{abstract}
In this paper, I will show that strict versions of Luck Egalitarianism and Democratic Egalitarianism are implausible since both claim that the object of egalitarian justice should single out one and only one value. On the contrary, weak versions are acceptable since they allow a plural composition of the egalitarian justice object.

This plural understanding of the object of egalitarian justice demands the justification of normative priorities since each conception would justify conflictive demands. In this article I will make three arguments to justify the normative priority of Democratic Egalitarianism over Luck Egalitarianism: a purely instrumental
\end{abstract}


one, another concerning expressive meaning of public policies and one last argument will show why we need a division of egalitarian moral work.

Keywords: Egalitarianism, respect, equal status, fairness, responsibility.

\section{Introducción}

La discusión contemporánea sobre la justicia distributiva está delimitada por dos grandes concepciones rivales. Mientras que una de ellas insiste en el eje de la responsabilidad individual para asegurarse los propios medios de vida y desarrollar su propio plan de vida, la segunda enfatiza el eje de las obligaciones redistributivas del Estado y de la comunidad política con respecto a sus ciudadanos. La pregunta que divide las aguas es, entonces, si un Estado igualitario debe mejorar la situación de aquellos individuos que tomaron decisiones imprudentes o improductivas. Esta sección reconstruirá el origen y desarrollo de las distintas respuestas a esta pregunta, prestando especial atención a cómo conciben el objeto de justicia igualitaria.

Una ilustración de esta pregunta puede hallarse en la literatura sobre la concepción rawlsiana de la igualdad distributiva que especifica el Principio de la Diferencia. Como es ampliamente conocido, este Principio considera que las desigualdades económicas son legítimas si y sólo si ellas redundan en un mayor beneficio de los miembros menos aventajados de la sociedad (Rawls 2004, p. 73). Dado que el criterio para identificar a los peor situados es un índice de bienes primarios y no un juicio sobre sus méritos individuales para estar en esa posición, el Principio de Diferencia justifica aplicaciones problemáticas, como la que imagina Will Kymlicka:

Imaginemos a dos personas con iguales talentos que comparten un mismo entorno social. Uno quiere jugar al tenis todo el día, por lo que, en una granja cercana, sólo trabaja lo suficiente para ahorrar el dinero necesario a fin de comprar tierra para una cancha de tenis y sostener su estilo de vida preferido (esto es, comida, vestido, equipamiento). La otra persona quiere una cantidad similar de tierra para cultivar un huerto, con el objeto de producir y vender hortalizas para sí misma y para otros. [...] El horticultor tendrá rápidamente más recursos que el tenista, si permitirnos que el mercado opere libremente. [...] Si el tenista no se beneficia de esta desigualdad, entonces el gobierno debería transferirle parte de los ingresos del horticultor, con objeto de igualar las rentas (2002, p. 72-3).

Este experimento mental pone de manifiesto la principal preocupación de los autores libertarios y los igualitaristas no rawlsianos: el principio de Diferencia justifica redistribuciones que benefician a aquellos individuos que acaban en una posición social desventajosa por sus propias decisiones. Después de todo, argumentan, el tenista amateur no tiene ningún impedimento físico y no hay condiciones severas 
de desempleo; su situación desventajosa es producto de su plan de vida y de ningún otro factor. Así, la operatoria del Principio de la Diferencia justificaría que los individuos responsables y que se esfuerzan (el horticultor) financien las decisiones libres de quienes deciden voluntariamente esforzarse menos.

A partir de la aparente fuerza intuitiva del ejemplo, ${ }^{1}$ las posteriores concepciones de justicia igualitaria intentaron generar parámetros distributivos capaces de distinguir entre los estados a los cuales un individuo llega mediante su propia elección y los estados a los que llega por circunstancias que están más allá de su control. Así, la primera situación no exigiría una redistribución hacia los peor situados pero ésta sí se justificaría en la segunda. Por ejemplo, si un individuo nació con una cierta discapacidad genética que no le permite trabajar, entonces es víctima de la mala suerte. Por lo tanto, debería recibir una compensación. Al contrario, aquellos individuos que, en un contexto de amplia accesibilidad al empleo, no realizan ningún esfuerzo para trabajar no deberían ser beneficiarios de ninguna redistribución: su situación desventajosa es producto de su propia decisión.

Numerosos autores (Ronald Dworkin, Gerald Cohen, Richard Arneson, John Roemer, etc.) diseñaron parámetros redistributivos que satisfagan dos condiciones: neutralizar los efectos penetrantes de la suerte en las oportunidades individuales y, al mismo tiempo, permitir las desigualdades surgidas de las elecciones responsables de los individuos. Sin autoadscribirse a una concepción igualitarista definida, cada uno de ellos utilizó distintas métricas de la igualdad (recursos, acceso a la ventaja, oportunidades para el bienestar, etc.) y distintos principios de redistribución (prioritarianismo, igualitarismo, etc.). A pesar de esta heterogeneidad, todas estas concepciones fueron agrupadas bajo la etiqueta de "Igualitarismo de la Suerte"2 en "What is the Point of Equality" de Elizabeth Anderson, un artículo esencial para la comprensión del desarrollo contemporáneo de la discusión. Allí, el Igualitarismo de la Suerte quedó caracterizado por suscribir dos tesis fundamentales:

1) Las desigualdades en las ventajas que pueden disfrutar los individuos son aceptables si se derivan de las elecciones que los individuos realizaron voluntariamente.

2) Las desigualdades en las ventajas que pueden disfrutar los individuos son inaceptables si se derivan de rasgos no elegido de las circunstancias individuales (Anderson 1999, pp. 288-9). ${ }^{3}$

\footnotetext{
${ }^{1}$ Sin embargo, véase Hinton (2001), pp. 84-85 para un cuestionamiento de la construcción del ejemplo y de su fuerza intuitiva.

2 De hecho, Ronald Dworkin (2002), pp. 115-8 rechazó terminantemente que pudiera catalogarse a su concepción como algún tipo de Igualitarismo de la Suerte.

3 Una reconstrucción similar puede hallarse en Scheffler (2003), p. 5. Richard Arneson aceptó de buen grado la etiqueta de "igualitarista de la suerte" pero, no obstante, reformuló las tesis centrales de esta concepción. Una de sus tesis definía el principio de la redistribución (la discusión entre un principio
} 
De acuerdo con Elizabeth Anderson, el Igualitarismo de la Suerte justifica redistribuciones que tienden hacia la igualdad pero lo hacen a un costo inaceptable, el de no mostrar el debido respeto hacia los ciudadanos de la comunidad. Por ejemplo, para poder redistribuir recursos que compensen la situación en la que dos individuos caen luego de un accidente que disminuyó radicalmente sus oportunidades, esta concepción debería evaluar si alguno de ellos actuó de manera irresponsable. El Estado, entonces, se vería comprometido a emitir juicios indiscretos sobre cuán responsable debería haber sido el individuo para evitar la situación en la que cayó (Anderson 1999, p. 310). Otra evidencia de esta falta de respeto puede hallarse, según la filosofa, en cómo el Igualitarismo de la Suerte trata a quienes acaban en una situación completamente desesperada debido a sus malas decisiones. Supóngase un individuo que sufre un grave accidente vehicular sin estar asegurado contra lesiones graves; tomó una mala decisión y, además, tuvo mala suerte. De acuerdo con el Igualitarismo de la Suerte, o bien este individuo debería ser dejado en el mismo lugar del accidente sin atención médica o bien podría ser forzado por el Estado a contratar un seguro contra esos hechos. Bajo esta última opción, la única alternativa a abandonar a las víctimas negligentes consistiría en apelar a intervenciones estatales paternalistas que reemplacen el mal juicio de los individuos (Anderson 1999, p. 301).

En la misma dirección de estas críticas, Jonathan Wolff argumentó que el Igualitarismo de la Suerte se compromete a dos tratamientos anti-igualitaristas: expresar una profunda falta de confianza hacia los individuos y exigir revelaciones vergonzosas por parte de los potenciales beneficiarios de las redistribuciones (Wolff 1998, pp. 108-9). Con respecto al primer problema, el Estado del Igualitarismo de la Suerte quiere evitar que los destinatarios de las redistribuciones sean "vividores" (free-riders) y, por lo tanto, les exige que no sólo reporten sino que confirmen convincentemente cómo llegaron a su situación. Un enfermo de cáncer de pulmón, por ejemplo, debería demostrar fehacientemente que nunca fumó o que no pudo evitar la compañía de quienes sí lo hacían. De acuerdo con Wolff, el mensaje de esta exigencia es claro: "cualquiera que está realizando un reclamo por beneficios de bienestar es, prima facie, objeto de sospecha: creemos que ellos podrían engañar al sistema si tan sólo pudieran salirse con la suya" (Wolff 1998, p. 111). Con respecto al segundo problema, considérese el siguiente ejemplo. En una economía próspera con un acceso considerable al empleo, un individuo no puede conseguir un trabajo; para convertirse en beneficiario de algún plan estatal de bienestar, deberá mostrar que no tiene ningún talento o aptitud para los empleos disponibles. "Esta [demostración pública] elimina cualquier jirón de dignidad que hubiera quedado en aquellos que

igualitarista estricto y un principio prioritarista) y la otra una interpretación del "suertismo" (luckism), según la cual, "la fuerza de cualquier razón moral para mejorar o empeorar la condición de un individuo puede ser amplificada o disminuida por algún factor que involucre una evaluación de la responsabilidad individual" (2004, p. 2). 
ya están en una posición desgraciada" (Wolff 1998, p. 114). Ambos problemas manifiestan, entonces, que la distinción entre lo que es producto de la elección y lo que es producto de la suerte implica políticas públicas en las que el Estado no trata respetuosamente a los individuos: sospecha de ellos, les exige demostraciones fehacientes de incapacidad y debilita seriamente las bases sociales de su autorrespeto.

Para Anderson y Wolff, estas consecuencias anti-igualitarias se deben a su origen teórico: si el Igualitarismo de la Suerte nació a la luz de las críticas a la inequidad del Principio de la Diferencia, entonces el "verdadero" igualitarista debe dejar de preocuparse por la equidad. Así, la única estrategia viable para no faltar el respeto a los individuos consistiría en reemplazar el objeto de las distribuciones del Igualitarismo de la Suerte por el de asegurar el respeto por todos los ciudadanos.

El "Igualitarismo Democrático" de Anderson (1999, p. 313) y el "Ethos Igualitario" de Wolff (1998, p. 105) defienden este reemplazo del objeto de la justicia igualitarista. Si bien pueden identificarse diferencias importantes y fundamentos normativos distintos, ${ }^{4}$ es posible aislar una tesis propositiva común: cada ciudadano tiene un derecho a las capacidades requeridas para evitar relaciones sociales opresivas y de explotación y para vivir como un ser humano capaz de perseguir sus propias concepciones del bien y participar de la vida económica, social y política de la vida de sus comunidades (Anderson 1999, p. 316). Puesto de otra manera, el Igualitarismo Democrático intenta especificar un "mínimo social" bajo el que ningún miembro de la comunidad política descienda y sea obligado a aceptar relaciones opresivas con los otros ciudadanos.

Este mínimo social no está ligado necesariamente a otros elementos de una teoría igualitarista; puede especificarse en métricas distintas, bajo distintos principio de distribución y puede surgir a partir de diferentes justificaciones normativas. Si bien en este artículo elijo simplificar esta heterogeneidad interna por razones de claridad expositiva, es importante señalar que la versión del Igualitarismo Democrático de Anderson no es la única posible. Por ejemplo, algunos de los autores que son considerados miembros de esta concepción han intentado mostrar que el Principio de la Diferencia rawlsiano se sigue de alguna concepción robusta de una sociedad democrática. Por ejemplo, Scheffler sugiere que el principio de distribución adoptado por un sistema de cooperación entre iguales debe ser más exigente que la mera superación de un umbral de suficiencia:

\footnotetext{
${ }^{4}$ Estas pueden hallarse en Wolff (2010), pp. 348-9. Allí menciona que el "Ethos Igualitario" no necesita aceptar la métrica de las capacidades, que su principio distributivo no debe ser necesariamente el suficientarismo y que el Igualitarismo Democrático de Anderson puede perder cierta capacidad crítica. Si bien estas diferencias son importantes para especificar una teoría de justicia distributiva concreta y específica, aquí me concentraré en sus puntos comunes.
} 
debe evitar excesivas variaciones en las porciones individuales de riqueza e ingreso y esto significará, entre otras cosas, que existen razones para oponerse a instituciones que dejen un espacio demasiado amplio para que las diferencias en las circunstancias sociales y naturales de los individuos se transformen en desigualdades económicas (2003, p. 23)..$^{5}$

El Igualitarismo Democrático implica dos consecuencias teóricas a la hora de pensar la definición y el diseño de la justicia igualitarista. Como mostraré a continuación, ellas hacen del Igualitarismo Democrático una versión antitética al Igualitarismo de la Suerte. La primera de estas consecuencias es que la responsabilidad individual deja de ser un criterio para ser beneficiario de una redistribución. Todos los individuos deberían tener asegurada la superación de un umbral mínimo de capacidades y ello no debe ser condicional a las elecciones que realizaron (Anderson 1999, pp. 316-8). Por ejemplo, si un individuo tomó una decisión imprudente, como no contratar un seguro médico dado un contexto de segura accesibilidad a los mismos, el Igualitarismo Democrático no evaluaría esa decisión y justificaría una redistribución con el siguiente mensaje al destinatario:

Usted tiene un valor moral que nadie puede ignorar. Reconocemos este valor en su derecho inalienable a nuestra ayuda en una emergencia. [...] Es libre de rechazar esta ayuda que le ofrecemos. Pero esa libertad no lo absuelve de su obligación de ayudar a los otros cuando sus necesidades médicas sean urgentes. Dado que esta es una obligación que le debemos a todos nuestros ciudadanos, cada uno deberá pagar un impuesto para este bien (Anderson 1999, p. 330).

De esta forma, el Igualitarismo Democrático abandona completamente el criterio de la responsabilidad y abraza la incondicionalidad de las redistribuciones. 6

\footnotetext{
5 A pesar de tales intentos, los últimos textos rawlsianos se inclinan a favor de mantener separadas las ideas de Principio de Diferencia y de mínimo social. Evidentemente, su convicción de que el Principio de la Diferencia fuera una idea perteneciente y aceptable para la cultura política pública había disminuido seriamente (principalmente Rawls, 2004, p. 180). Dado ello, Rawls rechazaba interpretarlo como una esencia constitucional aunque sí creía que un mínimo social debería serlo (2004, p. 216).

6 Este carácter incondicional es explícito en la concepción de Wolff (1998), p. 121. El mismo se desprende casi necesariamente del rechazo de las tesis del Igualitarismo de la Suerte y, en este sentido, es correcta la comparación que Wolff realiza con la "renta básica" de Van Parijs o con el Principio de Diferencia rawlsiano. En este sentido, considero que Anderson no extrae adecuadamente todas las consecuencias de su propia crítica cuando afirma que: "Contrariamente a la perspectiva de Van Parijs, los ciudadanos no se deben recíprocamente la libertad real para funcionar como holgazanes en la playa. Así, la mayoría de los ciudadanos con capacidades físicas normales tendrán acceso a los recursos divisibles que necesitan para funcionar si ganan un salario o una compensación equivalente que se les deba por satisfacer algún rol en la división del trabajo" (Anderson 1999, p. 321). Si el hecho de que los ciudadanos bien formados no elijan cumplir un rol en la división del trabajo es suficiente para negarles un subsidio o una redistribución que les permita acceder a funcionamientos valiosos, la distinción
} 
La segunda consecuencia del Igualitarismo Democrático es que la suerte no sólo deja de ser aquello que hay que neutralizar sino que también deja de considerarse como una razón para las redistribuciones. La distinción entre circunstancia y elección es abandonada ya sea porque implica una falta de respeto o porque implica una distinción metafísica y controvertida. ${ }^{7}$

Definidos de esta manera, el Igualitarismo de la Suerte y el Igualitarismo Democrático se presentan como dos concepciones incompatibles acerca de cuál debe ser el objeto de la igualdad. La primera afirma que el único objeto de la igualdad debe ser la equidad en la igualdad de oportunidades mientras que la segunda sostiene que ese objeto debe ser la defensa y preservación de relaciones interpersonales que manifiesten siempre el respeto por la agencia de los individuos. Como mostraré a continuación, esta forma de establecer los límites y elementos del objeto de justicia igualitaria necesariamente debe fallar, ya que reintroduce los problemas que dieron origen a cada una de estas concepciones.

\section{La implausibilidad de las versiones estrictas del Igualitarismo de la Suerte y el Igualitarismo Democrático}

En esta sección mostraré que las interpretaciones monistas del objeto igualitario producen inevitablemente teorías implausibles. Estas versiones estrictas, siguiendo la denominación de Alex Brown (2005, p. 298), consideran que el objeto igualitario debe identificar una única preocupación o un único valor: la equidad (en el caso del Igualitarismo de la Suerte) o el respeto (en el caso del Igualitarismo Democrático).

La reconfiguración del Igualitarismo de la Suerte que presentó Richard Arneson es un buen ejemplo de estas versiones estrictas. De acuerdo con ella, las faltas de respeto que el Igualitarismo Democrático identifica - la estigmatización o la expresión de un estatus menor - constituyen un daño grave pero que

debe ser comparado con otras razones en el cálculo de costos y beneficios morales que determinan la política correcta. [...] Algunas veces, el estigma impuesto a un individuo es parte de un paquete que, en su conjunto, le es beneficioso y que se justifica por esto.[...] El principio "Ninguna estigmatización, sin que importen las consecuencias" no es un candidato plausible con el estatus suficiente para ser incluido en el conjunto de principios morales fundamentales (2004, p. 14).

entre su concepción y el Igualitarismo de la Suerte se desvanece totalmente. En este mismo sentido, véase Brown (2005), p. 334 y Wolff (2010), p. 348.

7 Scheffler (2001), p. 17-21. 
Esta respuesta asume que las consideraciones acerca del respeto debido a los ciudadanos no deben influir sobre las distribuciones legitimadas por el igualitarismo aunque reconoce que ellas podrían tener algún peso a la hora de realizar un juicio habiendo tenido en cuenta todos los factores sobre las distribuciones aceptables. ${ }^{8}$ En este sentido, la posición de Arneson sería una versión estricta del Igualitarismo de la Suerte.

La propuesta de Arneson tiene dos problemas, uno interno y otro externo. El primero es que no muestra en qué sentido las políticas públicas igualitaristas incentivan o respetan la responsabilidad individual, uno de los objetivos del Igualitarismo de la Suerte.

De acuerdo con Arneson, las faltas de respeto que preocupan al Igualitarismo Democrático no tendrían por qué emitirse en la realidad práctica. El Estado podría legítimamente tener una justificación pública diferente de la justificación "real" si con eso se evita la expresión de una falta de respeto al individuo. Dado que los principios del Igualitarismo de la Suerte no necesariamente deberían funcionar como guías prácticas para decidir en circunstancias particulares, podría ocurrir que un Estado apele a otros principios para justificar redistribuciones concretas (2004, p. 14).

Esta distinción es escurridiza. Por supuesto, uno debería aceptar que una teoría filosófica es incapaz de alcanzar la especificidad y el nivel de detalle necesario para determinar la exacta política pública redistributiva que debe seguir un Estado; negar esta limitación práctica significaría desconocer la tremenda complejidad implícita en las redistribuciones económicas de una sociedad de masas. Sin embargo, a menos que se esté dispuesto a admitir la total irrelevancia práctica de una teoría política, este reconocimiento no debería convertir a la reflexión sobre la justicia distributiva en un ejercicio de mentes ociosas. Toda teoría política intenta ofrecer razones a favor de un principio determinado de justicia y éstas, más allá de la complejidad social y política, pueden figurar como fundamentos parciales a favor o en contra de una determinada política pública. Dado esto, sí importan las faltas de respeto que podrían expresar las políticas públicas derivadas de los principios del Igualitarismo de la Suerte.

Por otro lado, si el Estado se preocupa por estas expresiones y adopta políticas públicas derivadas de una justificación consistente con el Igualitarismo de la Suerte pero las justifica públicamente en base a otras razones, el Estado se convierte en hipócrita: lo que realmente quiere hacer y expresar se disfraza con ropajes más amigables.

\footnotetext{
8 Una propuesta similar puede hallarse en Clayton y Williams (1999, p. 446-7). Dado que el respeto es, de acuerdo con estos autores, un valor no igualitario, no creo correcto sostener que Arneson sea un defensor de una versión moderada del Igualitarismo de la Suerte como sostiene Brown (2005, p. 330).
} 
Ahora bien, un Estado hipócrita es tal porque tiene la creencia razonable de que la justificación "verdadera" de una política concreta podría ser rechazada o inaceptable para los ciudadanos. Al enmascarar esa justificación, el Estado engaña y manipula a los ciudadanos para que acepten una política pública que, aunque incrementaría idealmente su bienestar, no podría ser aceptada bajo la "verdadera" justificación. Por lo tanto, el Estado estaría impidiendo el juicio libre e informado de los ciudadanos. Así, es imposible ver en qué sentido las políticas públicas de esta versión estricta del Igualitarismo de la Suerte promueven la responsabilidad individual.

El segundo problema en la propuesta de Arneson tiene un carácter externo. Si el objeto de la igualdad y de la justicia distributiva está constituido únicamente por la equidad, serían tan igualitarias las políticas públicas humillantes como las que no lo son. Concebido de esta manera, el igualitarismo no podría considerar que existen razones vinculadas a la igualdad moral de los ciudadanos por las que ciertas distribuciones equitativas falten, sin embargo, el debido respeto a los individuos. Por ejemplo, no reconocería que la igualdad moral de un individuo se ve lesionada si él es obligado a arrodillarse ante el Ministro de la Igualdad para recibir su compensación por las desigualdades que no son producto de su propia elección. De la misma manera, tampoco habría razones igualitarias para rechazar un sistema de subsidios a la falta de talentos en el que el potencial beneficiario sea obligado a demostrar fehacientemente ante el Ministro de la Igualdad que no tiene ningún talento para los empleos disponibles. De esta forma, la versión estricta del Igualitarismo de la Suerte debe rechazarse por no reconocer que la expresión y el respeto por la igualdad moral de las personas constituyen razones a las que un igualitarista debe apelar.

Este rechazo no debe implicar que la versión estricta del Igualitarismo Democrático sea aceptable. Por el contrario, esta versión también es implausible. Según ella, el único objeto de la justicia igualitaria es evitar que se les falte el respeto debido a los individuos a través de prácticas que le exijan revelaciones vergonzosas, o que involucren medidas paternalistas, juicios estatales indiscretos o revelen una desconfianza inicial hacia el potencial beneficiario.

Esta versión estricta tiene tres problemas. En primer lugar, no considera relevante el aumento de bienestar de los beneficiarios de políticas paternalistas o humillantes. Así, consideraría igualmente irrespetuosa una política redistributiva que insulta a los individuos para compensarlos por su mala suerte a una política pública de no interferencia que no beneficia a esos individuos ni por tener mala suerte ni por ser ciudadanos. ${ }^{9}$

\footnotetext{
9 En este sentido, es importante reconocer la respuesta dworkiniana al rol excesivo que las consideraciones vinculadas con el significado expresivo de sus políticas podrían jugar dentro de una teoría de justicia distributiva: "El embuste de que la ayuda a los poco afortunados los insulta ha sido, desde hace siglos, un escudo para la indiferencia de los ricos y no para la dignidad de los pobres" (2002, p. 116).
} 
En segundo lugar, esta versión estricta podría ser autoderrotante ya que es compatible con un incremento masivo de la cantidad de vividores en una comunidad política. El propio Wolff reconoce este peligro al afirmar que

Si el respeto conduce a un rechazo de la recolección de datos y esto es explotado por los individuos, entonces hay una fuerte probabilidad de que se genere un espiral descendente que, eventualmente, termine en una situación en la cual pocos confiarán o respetarán al otro (Wolff 1998, p. 120).

El peligro es real. Supóngase que un eventual Ministro de Igualdad envía cartas a todos los potenciales beneficiarios (todos los ciudadanos) diciéndoles que, sin importar lo que hagan, tendrán subsidios que les permitirán superar un umbral de suficiencia para ser participantes de un esquema social, político y económico. La recepción de este mensaje podría producir la disminución del nivel de recursos necesarios para mantener esa política pública. Al menos a priori, se reduce el valor de los incentivos para que los individuos produzcan más y para que lo hagan responsablemente. Al mismo tiempo, aumentan las probabilidades de que algunos de los beneficiarios exploten el sistema redistributivo que les asegura el "mínimo social": todos recibirían el subsidio, independientemente de su esfuerzo para, por ejemplo, conseguir un empleo.

La proliferación de vividores es una consecuencia plausible e intuitiva de esta versión estricta del Igualitarismo Democrático y exige cierta reformulación de la concepción del "mínimo social". Sin embargo, creo pertinente introducir algunas calificaciones a este peligro.

El mundo poblado exclusivamente por vividores aprovechándose de las políticas redistributivas es la distopía favorita del libertarismo y su atractivo es tal que ha sido adoptada por el Igualitarismo de la Suerte. Su posibilidad en el mundo real es, no obstante, más bien ilusoria.

El grupo de los individuos que recibirían los beneficios del "mínimo social" no está constituido únicamente por individuos perfectamente sanos, educados en instituciones de alto nivel y que prefirieron una vida de holgazanería a mejorar sus oportunidades; tampoco está poblado exclusivamente por cínicos que obtienen placer en adquirir ventajas inequitativas de un sistema al cual no tienen ninguna voluntad de cooperar. Este grupo también está compuesto por aquellos ciudadanos que no pueden conseguir trabajo en condiciones de trabajo disponible - porque carecen de un talento con valor de mercado -, por aquellos que tienen discapacidades y enfermedades incapacitantes (ya sean producto de sus malas decisiones o de su mala suerte) y por quienes eligieron cuidar a otros. De hecho, dentro del grupo de los vividores también deben incluirse aquellos que "en nuestra sociedad ya son los más marginalizados y excluidos, que no ven ninguna ventaja en trabajar largas horas por exiguos salarios a las ordenes de otros" (Hinton 2001, p. 86). En las circunstancias rea- 
les de las sociedades desiguales, los beneficiarios de subsidios de bienestar o de políticas redistributivas ya sufren de una pérdida de auto-estima por estar en tal situación y ver cómo sus planes de vida se ven afectados drásticamente. Si se los somete a una batería de "pruebas anti-vividores" y luego se les deniega los beneficios de una redistribución o de un subsidio, pagan un costo demasiado alto: son condenados a su situación y no se les ofrece otra opción más que o bien humillarse públicamente o bien continuar una vida que no supera los umbrales de suficiencia que implican la vida de un ciudadano.

De esta manera, aunque reconozco la posible proliferación de vividores, considero que su probabilidad debe ser calificada y limitada por la existencia real de un grupo de vividores que, efectivamente, sea muy superior al del resto de los otros grupos y no que sea estipulada teóricamente como un argumento definitivo y destructivo del Igualitarismo Democrático. ${ }^{10}$

En tercer lugar, la versión estricta del Igualitarismo Democrático no podría explicar por qué cualquier concepción igualitarista se preocupa por justificar que algunos ciudadanos subsidien las redistribuciones requeridas. El Igualitarismo Democrático podría apelar a varias razones para esta justificación: desde el modelo de justificación recíproca de Anderson hasta que es una obligación inherente a ser miembro de un sistema de verdadera cooperación. No obstante, si la equidad es completamente eliminada de la cuestión de la justicia distributiva, las redistribuciones necesarias para satisfacer el umbral democrático podrían ser completamente inequitativas con quienes deben aportar recursos.

Esta sección del artículo llegó a una conclusión paradójica. Ambas versiones estrictas del Igualitarismo de la Suerte y del Igualitarismo Democrático son implausibles. Sin embargo, cada una de ellas ofrece razones válidas para un igualitarista. ¿Cómo construir, entonces, el objeto de justicia igualitarista? La solución más directa consiste en admitir que el objeto de la justicia igualitaria debe ser plural, es decir, que tanto consideraciones de respeto como de equidad deben ser incluidas a la hora de justificar y dirigir las políticas públicas.

Esta solución es directa pero ilusoria ya que reintroduce el problema en otro nivel de la reflexión. Si admiten que el objeto igualitarista debe ser plural, tanto el Igualitarismo Democrático como el de la Suerte adoptan tesis moderadas; según éstas no hay una "verdadera" o única idea central del valor de la Igualdad. Por ejemplo, Alex Brown sostuvo esta concepción plural de la igualdad según la cual

una sociedad de iguales es aquella en la cual mitigamos la influencia de la pura suerte en las vidas de los individuos, atribuimos los costos de las elecciones voluntarias a los

\footnotetext{
10 Una respuesta similar puede hallarse en Wolff: "El igualitarista tiene una razón por la que deben tolerarse ciertas formas de inequidad: ayudan a preservar una sociedad con respeto para todos" (1998, p. 120).
} 
individuos cuando eso sea posible pero, al mismo tiempo, luchamos por eliminar la pobreza extrema, la opresión y la falta de acceso a los funcionamientos valiosos" (Brown 2005, p. 331).

Si la equidad y el respeto pudiesen ser valores totalmente compatibles, la solución de Brown sería ideal. Sin embargo, la discusión entre ambas concepciones igualitaristas surgió, precisamente, porque esos valores no son siempre compatibles $\mathrm{y}$, de hecho, suelen entrar en conflicto. Dado esto, una comprensión plural del objeto de justicia igualitaria debe afrontar la tarea de establecer prioridades normativas. En la próxima sección mostraré que hay razones para asignar prioridad al Igualitarismo Democrático, es decir, que la expresión de respeto debe ser prioritaria sobre la equidad. ${ }^{11}$ Así, únicamente cuando las políticas redistributivas no condicionales del Igualitarismo Democrático sean suficientes para alcanzar el respeto debido, las consideraciones sobre la responsabilidad y la suerte tendrán relevancia normativa.

\section{Razones para establecer prioridades dentro del Igualitarismo}

Dado que la comprensión plural del objeto igualitario no resuelve los potenciales conflictos entre las demandas justificadas por la equidad y las legitimadas por el respeto, se hace perentoria la tarea de establecer prioridades normativas internas al igualitarismo. Esta sección desarrollará tres argumentos por los que el Igualitarismo Democrático puede reclamar legítimamente prioridad sobre el Igualitarismo de la Suerte.

El primer argumento para establecer esta prioridad es puramente instrumental. De acuerdo con éste, únicamente cuando el Igualitarismo Democrático asegura la satisfacción estable de precondiciones externas e internas para el desarrollo de una agencia responsable, los juicios sobre la responsabilidad del individuo pueden usarse como criterios para las redistribuciones igualitaristas.

La agencia responsable por el propio destino individual no puede postularse como una facultad innata. Por el contrario, es una capacidad cuyo desarrollo está fuertemente influenciado tanto por condiciones internas como externas. Mientras que las primeras se refieren a los recursos internos con los que el individuo toma sus decisiones (inteligencia, evaluación de alternativas, etc.), las segundas están relacionadas al contexto social y económico que limita o amplia sus opciones libres. Por ejemplo, la agencia responsable se ve reducida si las opciones de las que dispo-

\footnotetext{
11 En este sentido, el artículo se opone al pluralismo igualitario sin prioridades establecidas a priori que defiende Wolff (2010, p. 342-3). Como se argumentará, si estas prioridades no son establecidas, las distribuciones justificadas por consideraciones de equidad serían autocontradictorias.
} 
ne un individuo son muy poco valiosas o directamente triviales; la importancia que debe asignársele a su elección necesariamente disminuye. Del mismo modo, si sus opciones son escasas, si su capacidad para evaluarlas adecuadamente es limitada, su responsabilidad disminuye ya que, en algún sentido, esas circunstancias lo fuerzan a elegir de una determinada manera.

El mínimo social que especifica el Igualitarismo Democrático puede ser comprendido como el umbral mínimo de satisfacción de esas condiciones. Una vez superado este umbral, el agente posee un mínimo grado de control sobre su vida y sobre los estados a los que llega por sus decisiones. De esta manera, la prioridad de ese mínimo social implica dos límites. Por un lado, que sólo cuando ese umbral se supera, las consideraciones de responsabilidad y equidad exigen que el individuo se haga cargo del resultado de sus acciones. Por otro lado, que estas consideraciones no podrían conducir a que el individuo caiga bajo ese umbral.

Cabe señalar que este argumento instrumental presupone la validez de la versión moderada del Igualitarismo de la Suerte: el umbral mínimo es exigible en la medida en que su satisfacción produce un contexto en el que las consideraciones de responsabilidad y equidad pueden funcionar como criterios de la justicia distributiva.

Sin esta prioridad, el Igualitarismo de la Suerte conduce a resultados paradójicos ya que o bien tiende a negar que el individuo sea responsable o bien a aceptar la caída del individuo en situaciones que disminuyen radicalmente su agencia responsable. Estos resultados son manifiestos en la mayoría de las respuestas del Igualitarismo de la Suerte frente a posibles contraejemplos; éstas consisten en una reformulación tal del contraejemplo que siempre se resalte la existencia de un factor relevante que escapa al control del agente y que, por lo tanto, no justifica el resultado contraintuitivo. En este sentido, el Igualitarismo de la Suerte parece postular un criterio de responsabilidad que, en realidad, nunca puede ser satisfecho. 12

Al mismo tiempo, si no se evita que el individuo caiga bajo el mínimo social como resultado de sus propias elecciones, las precondiciones para el ejercicio de su agencia responsable no se verían satisfechas y se reducirían demasiado aquellas dimensiones de las que, a partir de ese momento, puede responsabilizárselo.

Ahora bien, las acciones públicas del Estado no sólo afectan la agencia individual por sus consecuencias directas sino también por sus consecuencias más indirectas, las relacionadas con su mensaje y significado expresivo. El segundo argumento para defender la prioridad del Igualitarismo Democrático está basado en este

12 El ejemplo más claro puede hallarse en Voigt (2007, p. 397-9) cuando se refiere a todos los factores que podrían incidir en la decisión imprudente de un agente y en sus resultados. Este peligro ya había sido resaltado por Anderson cuando afirmaba que, lejos de incentivar la responsabilidad, el igualitarismo de la suerte ofrecía al individuo "incentivos para negar la responsabilidad personal por sus problemas y para presentar su situación como una en la que él estaba indefenso frente a fuerzas incontrolables" (1999, p. 311). 
tipo de consecuencias. Su núcleo central es que los ciudadanos no pueden escapar del insulto y humillaciones emitidas públicamente.

Uno de los aparentes atractivos del Igualitarismo de la Suerte es que podría justificar redistribuciones a nivel global ya que, en última instancia, los individuos no tienen control sobre su lugar de nacimiento, los recursos de su país, etc. (Arneson 2004, p. 18). Las redistribuciones globales reducirían la desigualdad y mitigarían la fuerza de la pura suerte en las vidas de los individuos.

Por el contrario, el Igualitarismo Democrático no considera que la mera desigualdad despierte, por sí sola, razones para redistribuir. Éstas se activan únicamente cuando el tipo de relación entre los más aventajados y los menos aventajados no es meramente causal sino que ya está, de alguna manera, moralizada. La comunidad política organizada alrededor de un régimen democrático plantea un tipo especial de relaciones moralizadas, una relación igualitaria entre ciudadanos. Estas relaciones, ya sea que se den en el ámbito económico, social o político, están reguladas por un principio normativo, el del status igual. Según este principio, la igualdad del status de cada ciudadano es independiente de aquellas circunstancias que los diferencian como individuos únicos. A su vez, esta igualdad es incompatible con ciertos tratamientos o, al menos, la presencia de esos tratamientos (de dominación, de opresión, etc.) activa reclamos legítimos que tanto los otros ciudadanos como el Estado tienen obligación de tomar en cuenta.

Ese status igual determina el tipo de relaciones en la comunidad democrática y puede ser afectado por las propias decisiones del individuo, por las relaciones en las cuales participa y por su contexto socio-económico. Sin embargo, ninguna de estas relaciones puede destruir completamente el status igual; esto sólo puede hacerlo el Estado a través de sus acciones y del significado de sus mensajes.

Como ya se consideró, el Igualitarismo Democrático sostiene que las políticas del Igualitarismo de la Suerte faltan el respeto a los ciudadanos, es decir, que desconocen su status igual porque justifican revelaciones vergonzosas, juicios indiscretos y expresan una desconfianza inicial hacia los beneficiarios de sus compensaciones.

¿Qué hace que la emisión de estos juicios por parte del Estado tenga consecuencias desastrosas para el status igual de los ciudadanos? ¿Por qué ese status igual se mantiene si esos mismos juicios son emitidos por individuos aislados, ciudadanos de otros países o grupos sociales? La diferencia fundamental es que los "humillados" por individuos aislados, otros ciudadanos o grupos políticos tienen un ámbito donde asegurar ese status igual y escapar del insulto; pueden reafirmar su posición estructural simétrica en su pertenencia a una comunidad política democrática, que no asigna membrecía de acuerdo a un criterio de responsabilidad sino al hecho azaroso de haber nacido en esa comunidad. Por el contrario, cuando las políticas del Igualitarismo de la Suerte expresan estos insultos de una manera pública, el ciudadano queda expuesto, no sólo al resultado de la política en concreto, sino también a 
una humillación pública. Esta humillación pública no es casual ni no intencionada sino que se justifica con criterios que pueden ser rápidamente conocidos por los otros ciudadanos y que los habilita a reproducir esa humillación en las relaciones que mantienen. Puesto de otra manera, el individuo no tiene un ámbito plausible de dónde escapar de esa falta de respeto.

La prioridad del Igualitarismo Democrático significa que si las políticas redistributivas del Igualitarismo de la Suerte expresan faltas de respeto de las que los ciudadanos no pueden escapar, entonces no deberían ser impulsadas. Así, el establecimiento de esta prioridad rechaza la estrategia típica del Igualitarismo de la Suerte, según la cual estas faltas de respeto podrían compensarse, por ejemplo, a través de un mínimo social incondicional (Arneson 2004, p. 16). La prioridad implica que, en primer lugar, el Estado no puede emitir ese tipo de expresiones ya que disminuyen radicalmente el autorrespeto de los ciudadanos y que, en segundo lugar, el mínimo social no implica una compensación sino lo que es necesario para que los individuos mantengan seguro su igual status.

Dada esta respuesta, surgen dudas razonables: ¿no es, acaso, demasiado acotado el espacio legítimo que se le deja al Igualitarismo de la Suerte?; ¿no será que esta forma de establecer la prioridad reintroduce una versión estricta e implausible del Igualitarismo Democrático? La respuesta a ambas preguntas es negativa. La prioridad permite que en casos donde las políticas del Igualitarismo de la Suerte no emitan estas faltas de respeto, ellas sean las que regulen las redistribuciones. Por ejemplo, no parece ser una revelación vergonzosa que un individuo discapacitado por razones genéticas deba revelar su condición para acceder a los recursos públicos con los que se aseguraría un funcionamiento valioso. Del mismo modo, si un individuo no consigue empleo bajo condiciones de bajo desempleo y se le exige como condición para acceder a un subsidio por desempleo que asista a cursos de capacitación o a reuniones de concientización de sus derechos como ciudadano, el Estado no emite un juicio de desconfianza hacia él. Sí lo haría si, por ejemplo, se le exigiera que se presentara a una cantidad determinada de entrevistas laborales y tuviera que revelar que en ninguna de ellas se le reconoció alguna capacidad o talento.

Por último, el Igualitarismo Democrático debe ser prioritario con respecto al Igualitarismo de la Suerte ya que el primero operaría como una justificación general de por qué hay que redistribuir y el segundo funcionaría a un nivel de aplicación para explicar y legitimar redistribuciones concretas. Como enfatizaron los igualitaristas democráticos (Anderson 1999, p. 312-4; Schefller 2003, p. 21-4; Hinton 2001, p. 80-1), su concepción tiene una justificación parcial en la propia historia de los movimientos igualitaristas. Los Levellers, las luchas contra las formas de discriminación, contra una división entre ciudadanos de primera y de segunda, etc., fueron procesos políticos que colaboraron en la formación del ideal igualitario. Estos procesos son pobremente comprendidos si se considera que su principal reclamo es 
que es injusto considerar un factor azaroso - el color de piel, el origen familiar, etc. - como suficiente para tratar a un individuo inequitativamente. 13 Por el contrario, la mejor interpretación de estos procesos debe centrarse en la idea de que los individuos no debían ser discriminados, que no debían ser tratados como ciudadanos de segunda, que el voto no podía distribuirse de acuerdo a criterios censitarios y que cualquier comunidad política que tolerara o legalizara ese tipo de relaciones desiguales fallaba en respetar el igual status de los ciudadanos.

Aunque el argumento central de este trabajo señala que el status de igual ciudadanía puede ser asegurado a través de un mínimo social incondicional, es importante realizar una salvedad. Sería ingenuo creer que ese ideal relacional no puede ser afectado por la presencia de grandes desigualdades de oportunidades, ingreso y renta (Scheffler 2003, p. 24; Schemmel 2011). La desigualdad de ingreso puede traducirse rápidamente en desigualdad política, la desigualdad de oportunidades puede influir en el valor de los planes de vida disponibles y esto, a su vez, puede tener consecuencias negativas en la igualdad de status y en las relaciones que los individuos mantienen entre sí. Si esto es así, el Igualitarismo Democrático podría tener objetivos más ambiciosos que la mera garantía de un mínimo social como un instrumento para asegurar y hacer más estable la igualdad de status.

Dado esto, el Igualitarismo Democrático podría explicar y justificar la razón general por la cual se debe reducir la desigualdad pero, no obstante, tendría más problemas en justificar redistribuciones concretas, donde se le quita algo a alguien para dárselo a otra persona. El Igualitarismo de la Suerte, en cambio, podría ofrecer una justificación a esa redistribución concreta; "hay una parte del recurso que te da mejores oportunidades que es producto del azar, de que los otros cooperen con vos y que no está bajo tu control; esa parte será redistribuida hacia individuos que han tenido peor suerte y que obtienen menos ventajas y menos oportunidades por cooperar."

El punto central, entonces, de esta división del trabajo moral de un igualitarista es que, en definitiva, el Igualitarismo de la Suerte sólo podría operar como un instrumento para mantener segura y estable la igualdad de status de una comunidad política.

\section{Conclusión}

Este artículo mostró que el objeto del igualitarismo no puede ser monista, es decir, que no es posible identificar un único valor que agote el significado del trato igualitario hacia los individuos. Dada esta conclusión parcial, se mostró que una manera razonable de conciliar los dos valores típicamente conflictivos en la litera-

13 La reconversión que lleva a cabo Nicholas Barry de los "hechos de opresión" a factores que están más allá del control del agente (2006, p. 93-7) constituye un buen ejemplo de esta mala interpretación. 
tura igualitarista - el respeto y la equidad - es defender la prioridad de uno de ellos. La prioridad normativa que se estableció aquí coincide con la sugerida por las versiones moderadas del Igualitarismo Democrático y fue establecida en base a tres argumentos. El primero relacionado con las precondiciones necesarias para ejercer una agencia responsable, el segundo vinculado con el carácter penetrante e inescapable de los insultos y humillaciones emitidas por el Estado y el último se relacionó con una adecuada división del trabajo moral entre estas dos razones para redistribuir recursos.

Una forma interesante de mostrar las consecuencias prácticas de esta prioridad es reconsiderar el ejemplo desarrollado por Will Kymlicka con el que este mismo artículo comenzó y que servía para objetar las redistribuciones justificadas por el Principio de Diferencia rawlsiano. A diferencia de las razones esgrimidas por el Igualitarismo de la Suerte en contra de la conclusión rawlsiana, la prioridad del Igualitarismo Democrático implica que el horticultor no debe financiar - a través del pago de impuestos - parte del costo de las actividades del tenista. La razón no es tanto que se subsidiaría a un holgazán sino que, en primer lugar, el tenista tiene satisfechas las capacidades mínimas para ejercer una agencia responsable y, en segundo lugar, que su status como ciudadano igual está asegurado independientemente del subsidio del horticultor. Puesto de otra forma, dado que este status no se ve afectado, la redistribución sería inequitativa. Ahora bien, esa redistribución sí quedaría justificada por el Igualitarismo Democrático si, por ejemplo, el tenista viera seriamente comprometido su status como ciudadano igual o no se satisficieran las precondiciones para el ejercicio de su agencia responsable; esa redistribución sería exigible tanto si el tenista llegó a esa situación particular a través de sus propias decisiones o a través del impacto que la pura suerte tuvo en sus oportunidades.

Ahora bien, como ya se señaló, esta prioridad del Igualitarismo Democrático no aportó conclusiones acerca de si las redistribuciones deben tener un criterio suficientista, prioritarista, o igualitarista. Dado esto, la diferencia entre las conclusiones del Igualitarismo Democrático y del Principio de Diferencia rawlsiano podría verse eliminada si se estableciera que el status igual de los ciudadanos solo puede conseguirse evitando grandes desigualdades entre los peor y mejor aventajados de una sociedad. La resolución de esta cuestión deberá posponerse para un nuevo artículo. ${ }^{14}$

\section{Referencias bibliográficas}

Anderson, E. (1999): "What is the Point of Equality?, Ethics, 109, pp. 287-337. Anderson, E. (1999b): “Anderson Replies", Brown Electronic Article Review Service, http://www.brown.edu/Departments/Philosophy/bears/9912ande.html

\footnotetext{
14 Agradezco los valioso comentarios y sugerencias de Osvaldo Guariglia, Mariano Garreta Leclercq, Julio Montero, Ignacio Mastroleo y Federico Abal.
} 
ARnESON, R. (2004): "Luck Egalitarianism Interpreted and Defended", Philosophical Topics, 32, pp. 1-20.

BARRY, N. (2006): "Defending Luck Egalitarianism", Journal of Applied Philosophy, 23, pp. 89-107.

Brown, A. (2005): "Luck Egalitarianism and Democratic Equality", Ethical Perspectives, 12, pp. 293-339.

Clayton, M., Williams, A. (1999): "Egalitarian justice and interpersonal comparison", European Journal of Political Research, 35, pp. 445-64.

Cohen, J. (2003): "For a Democratic Society", en S. Freeman (ed.), Cambridge Companion to Rawls, Cambridge, Cambridge University Press, pp. 86-138.

Dworkin, R. (2002): “Sovereign Virtue Revisited”, Ethics, 113, pp. 106-143.

Hinton, T. (2001): "Must Egalitarians Choose Between Fairness and Respect?", Philosophy and Public Affairs, 30, pp. 72-87.

Kymlicka, W. (2002): Contemporary Political Philosophy. An Introduction, Oxford, Oxford University Press.

Rawls, J. (2004): La justicia como Equidad. Una reformulación., Buenos Aires, Paidós.

SCHEFFler, S. (2003): "What is Egalitarianism", Philosophy and Public Affairs, 31, pp. 5-39.

Schemmel, Ch. (2011): "Why Relational Egalitarians Should Care About Distribution", Social Theory and Practice, 37, pp. 365-90.

Voigt, K. (2007): "The Harshness Objection: Is Luck Egalitarianism Too Harsh on the Victims of Bad Luck?", Ethical Theory and Moral Practice, 10, pp. 389-407

WolfF, J. (1998): "Fairness, Respect, and the Egalitarian Ethos", Philosophy and Public Affairs, 27, pp. 97-122.

WolfF, J. (2010): "Fairness, Respect and the Egalitarian Ethos Revisited", The Journal of Ethics, 14, pp. 335-50.

Facundo García Valverde

Universidad de Buenos Aires

Consejos Nacionales de Investigaciones Tecnológicas y Científicas

fgarciavalverde@gmail.com 